\title{
Ethanol extract of Chaenomeles speciosa Nakai induces apoptosis in cancer cells and suppresses tumor growth in mice
}

\author{
GENDONG YAO $^{1}$, CHAOQI LIU $^{2}$, HONGQI HUO $^{1}$, AIMIN LIU $^{1}$, BAIRUI LV $^{1}$, CAN ZHANG $^{1}$, \\ HAIDONG WANG ${ }^{1}$, JINNONG LI $^{3}$ and LIANMING LIAO ${ }^{3}$ \\ ${ }^{1}$ Department of Biological Therapy, Central Hospital of Handan City, Handan, Hebei 056001; \\ ${ }^{2}$ Molecular and Biology Institute, Three Gorges University, Yichang, Hubei 443002; ${ }^{3}$ Institute of Oncology, \\ Academy of Integrative Medicine, Fujian University of Traditional Chinese Medicine, Fujian, Fuzhou 350102, P.R. China
}

Received November 10, 2012; Accepted April 19, 2013

DOI: $10.3892 / 01.2013 .1340$

\begin{abstract}
Chaenomeles speciosa Nakai is commonly used in traditional Chinese medicine for a variety of health-promoting effects. The present study aimed to investigate the antitumor effects of Chaenomeles speciosa Nakai. The tumor-inhibitory activity of the ethanol extract of Chaenomeles speciosa Nakai (EEC) was evaluated by in vitro growth assays of tumor cells and in vivo $\mathrm{H}_{22}$ tumor formation assays in mice. Mitochondrial membrane potential and DNA ladder assays were used to detect tumor cell apoptosis in the presence of EEC. To investigate the cellular targets of EEC, the immunomodulatory genes PD-L1, Foxp3 and TGF- $\beta$ were detected in the tumor tissue using reverse transcription polymerase chain reaction (RT-PCR). Immune responses were determined by hemolysis and lymphocyte proliferation assays. EEC markedly inhibited the proliferation of the $\mathrm{H}_{22}$ cells in a dose-dependent manner. Moreover, it induced DNA fragmentation and decreased the mitochondrial membrane potential. In vivo, EEC inhibited tumor growth and enhanced the immune responses in mice, while the expression of PD-L1, Foxp3 and TGF- $\beta$ was inhibited in the tumor tissue. These results provide the first evidence that EEC may inhibit tumor growth by directly killing tumor cells and enhancing immune function. Thus, it is a natural source for safe anticancer medicine.
\end{abstract}

\section{Introduction}

Chaenomeles speciosa Nakai (C. speciosa Nakai) has been used in traditional Chinese medicine for thousands of years to treat a variety of diseases, including sunstroke, edema and

Correspondence to: Dr Gendong Yao or Dr Hongqi Huo, Biological Therapy Department, Central Hospital of Handan City, No. 15 Zhonghua South Street, Handan, Hebei 056001, P.R. China

E-mail: cngdy@hotmail.com

E-mail: 13931018801@163.com

Key words: Chaenomeles speciosa Nakai, immune, apoptosis, cancer, mitochondrial membrane potential arthralgia. During the past decades, $C$. speciosa Nakai has been employed to treat diarrhea (1) and hepatitis (2). More recently, C. speciosa Nakai has also been used to treat arthritis (3-5). Studies have revealed that $C$. speciosa Nakai has antioxidant and immunomodulatory properties $(6,7)$.

In addition, Chinese herbalists have used C. speciosa Nakai to treat cancer, particularly hepatocellular carcinoma. Curative treatments, including surgery, local destruction techniques and liver transplantation, for hepatocellular carcinoma (HCC) are only achievable in certain patients. The majority of patients must undergo chemotherapy. Although chemotherapy has been shown to improve the survival of patients with HCC, there are several serious side-effects and drug resistance may occur. These two obstacles to more successful therapeutic outcomes have been major challenges for oncologists. The challenge of identifying new therapeutic approaches that alleviate the adverse effects of chemotherapy, while also improving their efficiency, is clear and urgent. Consequently, the present study investigated whether $C$. speciosa Nakai extracts may be used for the treatment of HCC. The present study investigated the effects of the ethanol extract of $C$. speciosa Nakai (EEC) in inhibiting tumor growth in vivo and in vitro.

\section{Materials and methods}

Materials. RPMI-1640 medium and fetal bovine serum were obtained from Invitrogen (Carlsbad, CA, USA). Unless stated otherwise, all other chemicals were obtained from SigmaAldrich (Zwijndrecht, the Netherlands).

Preparation of EEC. A total of $2 \mathrm{~kg}$ field-raised, air-dried C. speciosa Nakai was ground to a fine powder and added to $4,000 \mathrm{ml}$ ethanol [final ethanol concentration $60 \%(\mathrm{w} / \mathrm{v})$ ] for extraction for $1 \mathrm{~h}$ at $75^{\circ} \mathrm{C}$. The extract was incubated in a rotary evaporator until all of the ethanol had evaporated. The extract was then solubilized in saline and used for the present experiments. Overall, $1 \mathrm{ml}$ solution contained extract that was equal to $0.2 \mathrm{~g}$ raw $C$. speciosa Nakai.

In vivo tumor model. Kunming mice were obtained from the Hubei Laboratory Animal Center (Wuhan, China). The mice had free access to pellet food and water. The animals 
Table I. Oligonucleotide primers.

Gene

Primer sequences $\left(5^{\prime}-3^{\prime}\right)$

PD-L1

AGG CAA GCT TAT GTG GGT CCG GCA GGT AC

Foxp3 AGG CGA ATT CTC AAA GAG GCC AAG AAC AAT

TGF- $\beta$

CCC TTT CAC CTA TGC CAC CCT

GCT CCC TTC TCG CTC TCCAC

$\beta$-actin

ACG GCA TGG ATC TCA AAG AC

GTG GGT GAG GAG CAC GTA GT

TCA CCC ACA CTG TGC CCC ATC TAC GA

CAG CGG AAC CGC TCA TTG CCA ATG G

were acclimated to laboratory conditions at a temperature of $18-25^{\circ} \mathrm{C}$, with a relative humidity of 55 to $65 \%$ and a $12-\mathrm{h}$ light/dark cycle, for one week prior to the experiments. All animal experiments were approved by the Institutional Animal Control and Utilization Committee of the Central Hospital of Handan City.

The murine $\mathrm{H}_{22}$ cell line was obtained from the School of Basic Medical Science, Peking University (Beijing, China). Cells were cultured in Dulbecco's modified Eagle's medium (Gibco Laboratories, Grand Island, NY, USA) supplemented with $10 \%$ fetal bovine serum, penicillin and streptomycin (10 U/1, Gibco Laboratories) in a humidified atmosphere with $5 \% \mathrm{CO}_{2}$ at $37^{\circ} \mathrm{C}$. The hepatoma model was established by the subcutaneous inoculation of $\mathrm{H}_{22}$ cells ( $1 \times 10^{6}$ cells per mouse) into the right flank of the mice (8). At $48 \mathrm{~h}$ post-inoculation, the mice were randomly divided into three groups: i) the vehicle-treated control group, which received $0.5 \mathrm{ml}$ saline by gavage; ii) the EEC group, which received $0.5 \mathrm{ml} \mathrm{EEC}$; and iii) the cisplatin group, which received $5 \mathrm{~g} / \mathrm{kg}$ cisplatin intraperitoneally. Another eight mice, which were not inoculated with $\mathrm{H}_{22}$ cells, served as normal controls.

Red blood cells (RBCs; $5 \% 0.2 \mathrm{ml}$ per mouse) were injected into the peritoneal cavity on day 14 . All the mice were sacrificed at day 18 and the tumors were excised and weighed. The tumor inhibition rate was calculated according to the formula: inhibition rate $(\%)=(1-$ tumor weight in test group / tumor weight in control) $\mathrm{x} 100$.

Hemolysis assay. Sheep RBCs (20\%) were prepared with natural saline. The RBCs $(0.2 \mathrm{ml} 20 \%)$ were injected intraperitoneally into the mice. After four days, the specific IgM of the serum was detected as previously described (9). Briefly, $100 \mu 1$ 50X diluted mouse serum, $50 \mu 1$ 10X diluted complement and $50 \mu 15 \%$ sheep RBCs were added to the ELISA plate and incubated for $30 \mathrm{~min}$ at $37^{\circ} \mathrm{C}$. Following centrifugation, $150 \mu \mathrm{l}$ supernatant was transferred to a 96 -well plate to detect the absorbance at $\mathrm{OD}_{415}$. The $50 \%$ hemolysin value $\left(\mathrm{HC}_{50}\right)$ was calculated as follows: $\mathrm{HC}_{50}=$ sample dilution $x \mathrm{OD}_{\text {sample }} /\left(\mathrm{OD}_{\mathrm{RBC}} / 2\right)$. $\mathrm{OD}_{\mathrm{RBC}}$ was the $\mathrm{OD}$ value of the complete lysis of the RBCs.

Flow cytometry. Splenocytes were prepared and cultured in 24-well plates for $48 \mathrm{~h}$, then the cells were washed and fixed in $70 \%$ alcohol overnight at $4^{\circ} \mathrm{C}$. The cells were washed with PBS and $500 \mu 1 \mathrm{RNase}(30 \mu \mathrm{l} / \mathrm{ug})$ was added into Eppendorf tubes for $30 \mathrm{~min}$. Finally, propidium iodide dye was added in a dark room $(10,11)$ and the cell cycle was analyzed using flow cytometry (FCM). The lymphocyte proliferation rate $(\%)$ was calculated as follows: proliferation rate $(\%)=\left[\left(\mathrm{S}+\mathrm{G}_{2} \mathrm{M}\right) /\left(\mathrm{G}_{0 / 1}+\mathrm{S}+\mathrm{G}_{2} \mathrm{M}\right)\right] \times 100$.

Reverse transcription-polymerase chain reaction ( $R T-P C R)$. The $\mathrm{H}_{22}$ tumor tissues were collected and the total RNA was isolated using the RNase mini kit (Invitrogen). First-strand cDNA was synthesized from the total RNA with Super Script II reverse transcriptase (Invitrogen) using oligodT as the reverse primer.

The cDNA was amplified by PCR in a programmable DNA thermal cycler for 30 cycles $\left(95^{\circ} \mathrm{C}\right.$ for $3 \mathrm{~min}, 95^{\circ} \mathrm{C}$ for $30 \mathrm{sec}$, $55^{\circ} \mathrm{C}$ for $30 \mathrm{sec}$ and $72^{\circ} \mathrm{C}$ for $30 \mathrm{sec}$ ). The primer sequences used for the PCR are shown in Table I.

Proliferation assay. The percentage of growth inhibition was determined with the 3-(4,5-dimethylthiazol-2-yl)-2,5-diphenyltetrazolium bromide (MTT) assay (12). Hepatocellular carcinoma $\mathrm{H}_{22}$ cells $(4,000$ cells/well) were seeded into 96-well plates and treated with EEC. The cells were incubated overnight at $37^{\circ} \mathrm{C}$ with $5 \% \mathrm{CO}_{2}$. Subsequently, $100 \mu \mathrm{MTT}$, at a concentration of $2.5 \mathrm{mg} / \mathrm{ml}$, was added to each well and the cells were incubated for an additional $4 \mathrm{~h}$. The supernatant was then aspirated and dimethyl sulfoxide was added to the wells to dissolve the precipitate. The absorbance was determined at $570 \mathrm{~nm}$ using a micro-plate reader (Multiskan Spectrum; Thermo Electron Corporation, Vantaa, Finland). The cell survival rate $(\%)=100 \times \mathrm{OD}_{\mathrm{EEC} \text { group }} / \mathrm{OD}_{\text {control group }}$.

DNA fragmentation assay. The $\mathrm{H}_{22}$ cells were cultured in the presence or absence of EEC for $48 \mathrm{~h}$, then gently scraped and harvested by centrifugation. The cells were incubated for $20 \mathrm{~min}$ in DNA fragmentation lysis buffer [50 $\mathrm{mmol} / 1$ Tris- $\mathrm{HCl}$ (pH 8.0), $20 \mathrm{mmol} / \mathrm{l}$ ethylenediaminetetraacetic acid and $0.5 \%$ Triton $\mathrm{X}-100$ ] on ice. The cells were then centrifuged at $12,000 \mathrm{x} \mathrm{g}$ for $30 \mathrm{~min}$.

DNA was extracted with a mixture of phenol and chloroform (1:1) and precipitated with twice the volume of cold ethanol and sodium acetate. The precipitates were resuspended in $10 \mu \mathrm{l}$ $10 \mathrm{mM}$ Tris (pH 7.8) and $1 \mathrm{mM}$ EDTA buffer and incubated for $30 \mathrm{~min}$ at $37^{\circ} \mathrm{C}$ with $1 \mu \mathrm{g} / \mathrm{ml}$ RNase (Roche Molecular 
A

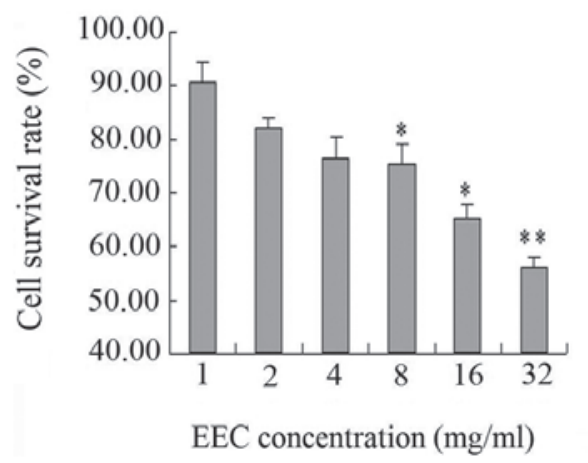

B

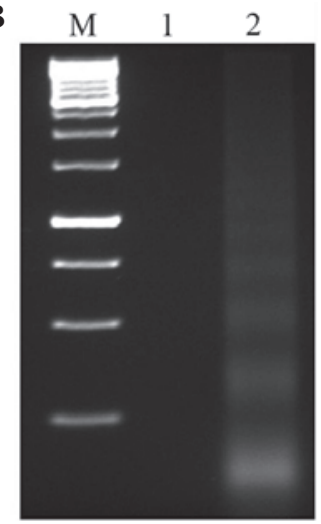

C

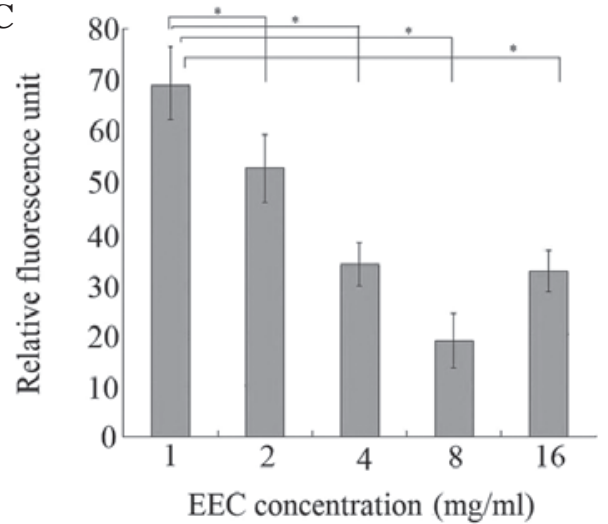

Figure 1. Antiproliferative and apoptotic effect of EEC on cancer cells. (A) $\mathrm{H}_{22}$ cells $\left(5 \times 10^{4}\right)$ were plated in 96 -well culture plates. Subsequent to $24 \mathrm{~h}$, the medium was changed to fresh medium and treated with saline alone or EEC at the indicated doses. Following $48 \mathrm{~h}$ of treatment, the cells were analyzed by MTT assay. (B) The effect of EEC on the DNA fragmentation of the $\mathrm{H}_{22}$ cells. Ladders were detected by $1.5 \%$ agarose gel electrophoresis. M, 1K DNA marker; lane 1, untreated $\mathrm{H}_{22}$ cells; lane 2, $\mathrm{H}_{22}$ cells treated with EEC. (C) Following $30 \mathrm{~min}$ of incubation with DiOC6 $(100 \mathrm{nM})$ for $\Delta \psi \mathrm{m}$, the intracellular fluorescence intensity was measured. Results represent the mean \pm SEM from three independent experiments. ${ }^{*} \mathrm{P}<0.05$ vs. control; ${ }^{* * *} \mathrm{P}<0.01$ vs. control. EEC, ethanol extract of Chaenomeles speciosa Nakai; $\Delta \psi \mathrm{m}$, mitochondrial membrane potential.

Biochemicals, Indianapolis, IN, USA) to remove the RNA. The DNA pellets were electrophoresed for $90 \mathrm{~min}$ at $100 \mathrm{~V}$ on $2 \%$ agarose gels. The gel was stained with ethidium bromide and the DNA fragments were visualized under ultraviolet light.

Measurement of mitochondrial membrane potential $(\Delta \psi m)$. The $\mathrm{H}_{22}$ cells $\left(2 \times 10^{4}\right.$ cells/well) were seeded into a 96-well plate and incubated overnight at $37^{\circ} \mathrm{C}$, with $5 \% \mathrm{CO}_{2}$. Subsequently, the cells were treated with various concentrations of EEC and incubated for an additional $10 \mathrm{~h}$ (13). To measure $\Delta \psi \mathrm{m}$, the cells were incubated with DiOC6 (100 nM; Molecular Probes, Eugene, OR, USA) during the last 30 min of treatment. DiOC6 is a fluorescent dye that is incorporated into the mitochondria in a $\Delta \psi \mathrm{m}$-dependent manner. Once the cells had been sufficiently washed, the fluorescence intensity was determined using a multifunctional micro-plate reader (14).

Statistical analysis. All values are expressed as the mean results of the triplicate experiments \pm standard deviation. The unpaired Student's t-test was used to identify differences between the groups. $\mathrm{P}<0.05$ was considered to indicate a statistically significant difference. SPSS 10.0 (SPSS, Inc., Chicago, IL, USA) was used for the statistical analyses.

\section{Results}

EEC has marked antiproliferative and apoptotic effects in cancer cells. The effect of EEC on the growth of cancer cells is expressed as the percentage of cell viability relative to the control. As shown in Fig. 1A, EEC inhibited the proliferation of the $\mathrm{H}_{22}$ cells in a dose-dependent manner. Compared with the saline-treated controls, EEC at a dose of $32 \mathrm{mg} / \mathrm{ml}$ caused $57.5 \%$ inhibition of $\mathrm{H}_{22}$ cell proliferation $(\mathrm{P}<0.001)$. The cells treated with EEC showed typical apoptotic morphologies, including cell shrinkage and rounding and cell membrane blebbing, as well as nuclear fragmentation and condensation (data not shown). Apoptosis was characterized by the activation of endogenous endonucleases with the subsequent cleavage of chromatin DNA into internucleosomal fragments of 180 to
200 bp. The extracted cell DNA was detected by agarose gel electrophoresis. Fragmented DNA was clearly observable in the $\mathrm{H}_{22}$ cells following treatment with EEC for $48 \mathrm{~h}$, whereas the cells did not produce ladders without treatment. Thus, the apoptotic effect of EEC on the tumor cells was further demonstrated by DNA fragmentation (Fig. 1B).

Mitochondrial damage is significant in cell apoptosis. Therefore, to determine whether $\Delta \psi \mathrm{m}$ is involved in the regulation of apoptosis induced by EEC, the fluorescent lipophilic cation DiOC6 was used as an indicator of the energy state of the mitochondria. As shown in Fig. 1C, EEC treatment led to a rapid drop in mitochondrial energy, as demonstrated by a decrease in fluorescence from the baseline following $12 \mathrm{~h}$ of treatment (M1, 47.55\% in the control cells vs. $77.43 \%$ in the EEC-treated $\mathrm{H}_{22}$ cells; the $\Delta \psi \mathrm{m}$ peak shifted to the left, indicating that fewer cells retained DiOC6 in their mitochondria). These results suggested that the inhibitory effect of EEC on tumor cell growth may be through the induction of apoptosis.

EEC inhibits tumor growth in vivo. The antitumor activity of EEC was investigated in the $\mathrm{H}_{22}$ murine hepatoma model. The results showed that EEC and cisplatin significantly inhibited tumor growth compared with the vehicle-treated group, with inhibitory rates of $39.82 \pm 4.98$ and $58.33 \pm 9.29 \%$, respectively $(\mathrm{P}<0.05$ compared with vehicle-treated group; Table II). These data indicate that EEC has the ability to inhibit the growth of $\mathrm{H}_{22}$ cells in vivo.

The gross toxicity of EEC and cisplatin was then compared using the body weights of the mice. The body weights were 19-21 $\mathrm{g}$ at baseline and were similar among the three groups. Subsequent to 18 days of treatment the differences in net body weight per mouse (body weight - tumor weight) were statistically significant among the three groups (Table II). The net body weight of the EEC group was significantly higher than that of the cisplatin group, indicating that EEC has less severe adverse reactions compared with cisplatin.

EEC enhances immunity in mice. To further investigate the mechanism by which EEC inhibits tumor growth, lymphocyte 
Table II. Inhibitory effect of EEC on $\mathrm{H}_{22}$ murine hepatoma cell growth in mice.

\begin{tabular}{lcccc}
\hline Group & $\begin{array}{c}\text { Body } \\
\text { weight }(\mathrm{g})\end{array}$ & $\begin{array}{c}\text { Tumor } \\
\text { weight }(\mathrm{g})\end{array}$ & $\begin{array}{c}\text { Net body weight (g) } \\
\text { (body weight - tumor weight) }\end{array}$ & $\begin{array}{c}\text { Tumor inhibition } \\
\text { rate }(\%)\end{array}$ \\
\hline Vehicle-treated & $32.91 \pm 5.11$ & $1.73 \pm 0.32$ & $31.18 \pm 4.79$ & - \\
EEC & $29.00 \pm 4.63$ & $1.04 \pm 0.13$ & $27.96 \pm 4.52^{\mathrm{a}}$ & $39.82 \pm 4.98$ \\
Cisplatin & $19.28 \pm 2.41$ & $0.72 \pm 0.12$ & $18.56 \pm 2.29^{\mathrm{a}}$ & $58.33 \pm 9.29$ \\
\hline
\end{tabular}

Data are presented as mean \pm standard deviation. ${ }^{\text {a }}<0.05$ vs. vehicle-treated group. EEC, ethanol extract of Chaenomeles speciosa Nakai.

Table III. Antibody production and inhibition of lymphocyte proliferation.

\begin{tabular}{lcc}
\hline Group & $\begin{array}{c}\text { Proliferation rate } \\
(\%)\end{array}$ & $\begin{array}{c}\mathrm{RBC} \text { antibody } \\
\left(\mathrm{HC}_{50}\right)\end{array}$ \\
\hline Normal & $63.75 \pm 8.93$ & $179.80 \pm 22.47$ \\
Vehicle-treated & $49.18 \pm 19.23$ & $110.34 \pm 13.79$ \\
EEC & $55.20 \pm 16.82^{\mathrm{a}}$ & $188.44 \pm 23.56^{\mathrm{b}}$ \\
Cisplatin & $39.78 \pm 19.79$ & $54.32 \pm 6.79$ \\
\hline
\end{tabular}

Data are presented as mean \pm standard deviation. ${ }^{\mathrm{a}} \mathrm{P}<0.05$; ${ }^{\mathrm{b}} \mathrm{P}<0.01 \mathrm{vs}$. cisplatin. EEC, ethanol extract of Chaenomeles speciosa Nakai.

A

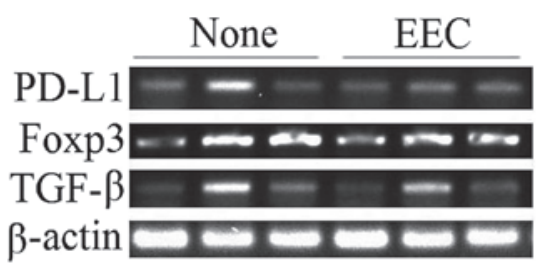

B

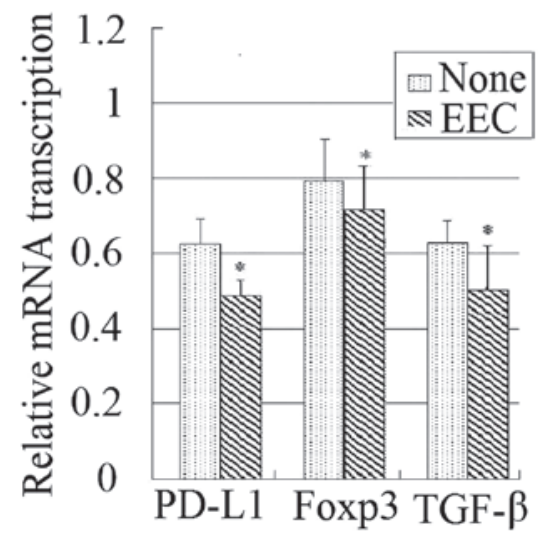

Figure 2. (A) Agarose gel electrophoresis of reverse transcription polymerase chain reaction products. (B) Gel bands in the digitized image were selected and their average gray-scale density measured. The results were compared between groups. ${ }^{*} \mathrm{P}<0.05$ vs. control. EEC, ethanol extract of Chaenomeles speciosa Nakai.

proliferative activity was evaluated using a flow cytometry assay. As shown in Table III, the cell cycle analysis showed that EEC enhanced lymphocyte proliferation. Moreover, the hemolysis assay showed that EEC significantly increased the production of $\mathrm{RBC}$ antibody $\left(\mathrm{HC}_{50}\right.$; Table III). Compared with the vehicle-treated group, cisplatin significantly decreased the production of RBC antibody. These data indicate that EEC inhibits tumor growth partially via enhancing host immunity.

EEC suppresses the expression of PD-L1, Foxp3 and TGF- $\beta$. PD-L1 is a ligand of programmed death 1 (PD-1), which is expressed on activated lymphocytes and negatively regulates the immune response. Foxp3 is specifically expressed on regulatory $\mathrm{T}$ (Treg) cells and suppresses effective lymphocyte activity. TGF- $\beta$ is a cytokine that activates the Treg cells. All of these factors are negative immunomodulatory factors. The present study observed that EEC decreases the expression levels of these three genes in the tumor tissues, as indicated by RT-PCR (Fig. 2).

\section{Discussion}

The present study demonstrated that EEC inhibits the growth of $\mathrm{H}_{22}$ cells in vivo and causes the apoptosis of cells in vitro. Furthermore, tumors isolated from the inoculated mice expressed more PD-L1, Foxp3 and TGF- $\beta$ in the vehicle-treated group compared with the EEC group, suggesting that EEC is able to inhibit the expression of negative immnoregulatory genes.

Despite advances in the understanding of the carcinogenic processes of cancer, the relatively low remission rate of chemotherapy, radiotherapy and immunotherapy have encouraged the scientific community to identify active medicinal compounds from herbal/natural sources. In the present study, it was demonstrated that EEC was able to suppress cancer cell growth through the induction of apoptosis, the inhibition of cell proliferation and the promotion of host immune function. This is the first study that clearly characterizes the antitumor properties of EEC in cancer cells and tumor xenografts.

It is not clear which compounds are responsible for the antitumor effects of EEC. Triterpenoids, flavonoids and organic acids are the main classes of compounds identified from C. speciosa Nakai (15-20). The major triterpenoids include 3-O-acetylursolic acid, 3-O-acetylpomolic acid, oleanolic acid and betulinic acid. Betulinic acid was initially characterized as a highly selective inhibitor of human melanoma cells and tumor growth through the induction of apoptosis (21). Subsequent research has shown that betulinic acid is an effective inhibitor of cell proliferation and that it induces apoptosis in numerous types of cancer cells (22). Oleanolic acid has also been shown to induce apoptosis in leukemia cells (23-26). 
Therefore, the antitumor effects of EEC may involve contributions by oleanolic acid and betulinic acid.

In order to further clarify the mechanism involved in the EEC-induced growth suppression of tumor xenografts, the immune function of tumor-bearing mice was investigate in the present study. EEC was observed to promote the production of immunoglobulin. Further investigation demonstrated that EEC was able to suppress the expression of PD-L1, Foxp3 and TGF- $\beta$. The transcription factor Foxp3 has a major role in the development of Treg cells and is critical for their suppressive function (27). Naive $\mathrm{CD} 4^{+} \mathrm{T}$ cells selected by Foxp3 during development in the thymus have the potential to be converted into functional Foxp $3^{+}$Treg [adaptive or induced Treg (iTreg)] cells in peripheral lymphoid organs or tissue culture. Thus, the decreased expression of Foxp3 in the EEC-treated tumors may indicate that there are fewer Treg cells in EEC-treated tumors compared with vehicle-treated tumors. In accordance with this finding, the expression of TGF- $\beta$, a factor that is critical in the induction of Foxp3 expression in vitro and in vivo, was also suppressed. Furthermore, the expression of PD-L1, the ligand of PD-1, was also suppressed by EEC. PD-1 is an inhibitory receptor that is expressed on activated lymphocytes and that regulates tolerance and autoimmunity. These findings suggest that the enhancement of immunity in EEC-treated tumor-bearing mice may be associated with the suppression of immune tolerance.

In addition, the promising antitumor effect of EEC was achieved without the toxicity and side-effects anticipated with cisplatin (e.g. a significant drop in body weight and immunosuppression), which further suggests that EEC has the potential to be established as novel adjuvant agent in cancer chemotherapy. At present, the fractionation of EEC is being performed to identify the fractions that contain the bioactive constituents responsible for the growth-inhibitory effects.

In summary, the present study demonstrated that EEC was able to inhibit cancer cell growth in vitro and in vivo. In contrast to orthodox chemotherapy using cytotoxic drugs, the use of this herbal extract imposes less toxicity while retaining antitumor effects. This indicated the possibility of further developing EEC as an adjuvant chemotherapeutic agent in cancer therapy.

\section{References}

1. Han B, Peng H, Yao Q, Zhou Y, Cheng M and Wang D: Analysis of genetic relationships in germplasms of Mugua in China revealed by internal transcribed spacer and its taxonomic significance. Z Naturforsch C 65: 495-500, 2010.

2. Liu S, Bai Z and Li J: Comprehensive evaluation of multi-quality characteristic indexes of Chaenomeles speciosa and $C$. sinensis fruits. Zhongguo Zhong Yao Za Zhi 37: 901-907, 2012 (In Chinese).

3. Dai M, Wei W, Shen Y and Zheng Y: Effect of total saponin of Haenomeles speciosa on hemorrheology of immunity arthritis in rats. Zhongguo Zhong Yi Yao Xin Xi Za Zhi 12: 20-21, 2002 (In Chinese)

4. Song YL, Zhang L, Gao JM, Du GH and Cheng YX: Speciosaperoxide, a new triterpene acid, and other terpenoids from Chaenomeles speciosa. J Asian Nat Prod Res 10: 217-222, 2008.

5. Dai M, Wei W, Wang N and Chen Q: Therapeutic effect of glucosides of Chaenomeles speciosa on adjuvant arthritis in rats. Zhongguo Yao Li Xue Tong Bao 3: 340-344, 2003 (In Chinese).
6. Sawai R, Kuroda K, Shibata T, Gomyou R, Osawa K and Shimizu K: Anti-influenza virus activity of Chaenomeles sinensis. J Ethnopharmacol 118: 108-112, 2008.

7. Yang Y, Li X, Yang Q, Wu Z and Sun L: Studies on chemical constituents of Chaenomeles speciosa (Sweet) Nakai (II). Di 2 Jun Yi Da Xue Xue Bao 10: 1195-1198, 2009 (In Chinese).

8. Thomas MB, Jaffe D, Choti M, et al: Hepatocellular carcinoma: consensus recommendations of the National Cancer Institute Clinical Trials Planning Meeting. J Clin Oncol 28: 3994-4005, 2010.

9. Kumarnsit E, Keawpradub N and Nuankaew W: Acute and long-term effects of alkaloid extract of Mitragyna speciosa on food and water intake and body weight in rats. Fitoterapia 77: 339-345, 2006.

10. Shimojo RY and Iwaoka WT: A rapid hemolysis assay for the detection of sodium channel-specific marine toxins. Toxicology 154: 1-7, 2000.

11. Guo B, Romero J, Kim BJ and Lee H: High levels of Cdc7 and Dbf4 proteins can arrest cell-cycle progression. Eur J Cell Biol 84: 927-938, 2005.

12. Zhang L, Xu H and Li S: Effects of micronization on properties of Chaenomeles sinensis (Thouin) Koehne fruit powder. Innov Food Sci Emerg Technol 10: 633-637, 2009.

13. Ros JM, Laencina J, Hellin P, Jordan MJ, Vila R and Rumpunen K: Characterization of juice in fruits of different Chaenomeles species. Lebenson Wiss Technol 37: 301-307, 2004.

14. Moongkarndi P, Kosem N, Kaslungka S, Luanratana O, Pongpan $\mathrm{N}$ and Neungton N: Antiproliferation, antioxidation and induction of apoptosis by Garcinia mangostana (mangosteen) on SKBR3 human breast cancer cell line. J Ethnopharmacol 90: 161-166, 2004.

15. Chen XZ, Cao ZY, Chen TS, Zhang YQ, Liu ZZ, Su YT, Liao LM and Du J: Water extract of Hedyotis Diffusa Willd suppresses proliferation of human HepG2 cells and potentiates the anticancer efficacy of low-dose 5 -fluorouracil by inhibiting the CDK2-E2F1 pathway. Oncol Rep 28: 742-748, 2012.

16. Hou XJ, Zhang N, Xiong SY, Li SG and Yang BQ: Extraction of BaChu mushroom polysaccharides and preparation of a compound beverage. Carbohydr Polym 73: 289-294, 2008.

17. Yamahara J, Yamada T, Kitani T, Naitoh Y and Fujimura H: Antianoxic action and active constituents of evodiae fructus. Chem Pharm Bull (Tokyo) 37: 1820-1822, 1989.

18. Hong YF, Sun LN and Guo XM: GC-MS analysis of ether extracts from three species of Chaenomeles fruits. Di 2 Jun Yi Da Xue Xue Bao 21: 749-752, 2000 (In Chinese).

19. Talapatra SK, Sarkar AC and Talapatra B: Two pentacyclic triterpenes from Rubia cordifolia. Phytochemistry 20: 1923-1927, 1981.

20. Liang GY, Gray AI and Waterman PG: Pentacyclic triterpenes from the fruits of Rosa sterilis. J Nat Prod 52: 162-166, 1989.

21. Pisha E, Chai H, Lee IS, et al: Discovery of betulinic acid as a selective inhibitor of human melanoma that functions by induction of apoptosis. Nat Med 1: 1046-1051, 1995.

22. Zou Q, Deng W, Jiang S, Zhang L, Peng S and Ding L: Studies on chemical constituents from fruits of Forsythia suspense. Zhongguo Zhong Yao Za Zhi 37: 57-60, 2012 (In Chinese).

23. Chintharlapalli S, Papineni S, Ramaiah SK and Safe S: Betulinic acid inhibits prostate cancer growth through inhibition of specificity protein transcription factors. Cancer Res 67: 2816-2823, 2007.

24. George VC, Kumar DR, Suresh PK and Kumar RA: Apoptosis-induced cell death due to oleanolic acid in HaCaT keratinocyte cells - a proof-of-principle approach for chemopreventive drug development. Asian Pac J Cancer Prev 13: 2015-2020, 2012.

25. Tan Y, Yu R and Pezzuto JM: Betulinic acid-induced programmed cell death in human melanoma cells involves mitogen-activated protein kinase activation. Clin Cancer Res 9: 2866-2875, 2003.

26. Zhang P, Li H, Chen D, Ni J, Kang Y and Wang S: Oleanolic acid induces apoptosis in human leukemia cells through caspase activation and poly(ADP-ribose) polymerase cleavage. Acta Biochim Biophys Sin (Shanghai) 39: 803-809, 2007.

27. Zheng Y and Rudensky AY: Foxp3 in control of the regulatory T cell lineage. Nat Immunol 8: 457-462, 2007. 